\title{
Experimental study on fatigue performance of Q420qD high-performance steel cross joint in complex environment
}

\author{
Haigen Cheng ${ }^{1,2} \cdot$ Cong Hu${ }^{1}$ (i) $\cdot$ Yong Jiang ${ }^{3}$
}

Received: 17 October 2020 / Accepted: 22 January 2021 / Published online: 4 February 2021

(c) The Author(s) 2021

\begin{abstract}
The steel structure under the action of alternating load for a long time is prone to fatigue failure and affects the safety of the engineering structure. For steel structures in complex environments such as corrosive media and fires, the remaining fatigue life is more difficult to predict theoretically. To this end, the article carried out fatigue tests on Q420qD high-performance steel cross joints under three different working conditions, established a $95 \%$ survival rate $S-N$ curves, and analyzed the effects of corrosive media and high fire temperatures on its fatigue performance. And refer to the current specifications to evaluate its fatigue performance. The results show that the fatigue performance of the cross joint connection is reduced under the influence of corrosive medium, and the fatigue performance of the cross joint connection is improved under the high temperature of fire. When the number of cycles is more than 200,000 times, the design curves of EN code, GBJ code, and GB code can better predict the fatigue life of cross joints without treatment, only corrosion treatment, and corrosion and fire treatment, and all have sufficient safety reserve.
\end{abstract}

Keywords Q420qD high-performance steel · Cross joint · Corrosive medium · High temperature of fire · Fatigue performance

\section{Introduction}

With the development of steel structure bridges in terms of light weight, high load-bearing capacity and large span in recent years, traditional bridge steel can no longer meet the demand. Q420qD high-performance steel is a new type of steel that China's independent innovation has the advantages of lower thickness, higher strength, and good ductility. It has been widely used in railway bridges across rivers and lakes and some large highway bridges (Liu et al. 2018).

These structures have been exposed to high humidity or high salt spray environment for a long time (Bhandari et al. 2015). Although the steel structure has a paint protection

Cong $\mathrm{Hu}$

hu1834680371@163.com

1 School of Civil Engineering and Architecture, East China Jiaotong University, Nanchang 330013, China

2 National Experimental Teaching Demonstration Center of Civil Engineering, East China Jiaotong University, Nanchang 330013, China

3 China Railway Shanghai Design Institute Group Co., Ltd., Shanghai 200000, China layer on the surface of the steel structure in the early stage of operation, as the service time increases, it is unavoidable to suffer from the influence of corrosive media (Kim et al. 2013). According to reports, about $15 \%$ of road steel bridges and $50 \%$ of railway steel bridges in Japan are replaced by corrosion (Yamaguchi et al. (2014)). Corrosion will not only reduce the effective cross-sectional area of the steel structure, but also cause stress concentration (Tohidi and Sharifi 2016), affecting the mechanical properties of the steel structure, such as significantly reducing the ultimate stress and fatigue strength (Jia et al. 2019). As one of the most important connection methods of steel bridges, welded joints are more sensitive to defects such as corrosion pits and cracks during the service process after the strength level of the bridge steel is improved (Zhang et al. 2016).

During the service period, steel bridges may even be eroded by fire caused by traffic accidents or natural factors (Song et al. 2016; Azhari et al. 2017). Although the existing fire protection technology has been widely used in practice, the heat generated by the fire will still be transferred to the steel. Under the action of high temperature of fire, steel structure is easy to lose strength, but in most cases, steel structure exposed to the outside after the action of high 
temperature of fire can still maintain most of its bearing capacity after cooling (Radu et al. 2018,2019; Zhu and Li 2017). Welding residual stress generated during the formation of welded joints, tensile residual stress is harmful to the fatigue process, and compressive residual stress can prolong the fatigue life (Wang et al. 2018,2020a; Cui et al. 2018). Under the action of high temperature of fire, the welded joint of steel bridge is an extremely weak part, but after the high temperature of fire, part of the residual strain in the welded joint will be released due to the effect of plastic deformation, which reduces the residual welding stress and affects the fatigue performance of the structure. Make an impact (Jiang et al. 2017; Wang et al. 2020b).

In the past few decades, scholars have mostly focused their research on the effect of a single environmental factor on the fatigue performance of welded structures, such as corrosion (corrosion time (Yang et al. 2016; Garbatov et al. 2014; Liu et al. 2021), corrosive medium (Thierry et al. 2016; Kang et al. 2011; Giorgetti et al. 2019; Klinesmith et al. 2007), corrosion conditions (Zhao et al. 2018; Gkatzogiannis et al. 2019; Huang et al. 2014)); temperature (high temperature (Daryan and Yahyai 2009; Zhang et al. 2020; Langschwager et al. 2017; Azari-Dodaran and Ahmadi 2019), room temperature (Zong et al. 2017; Luo et al. 2019; Su et al. 2019), and low temperature (Li et al. 2018; Zhang et al. 2018; Walters et al. 2016)). In actual engineering, the service environment of steel bridges is extremely complex, and the influence of a single environmental factor on its structural fatigue performance can no longer meet the needs of engineering design and evaluation. Therefore, the research on the fatigue performance of welded joints after considering the coupling effect of the two environmental factors of corrosive medium and fire and high temperature is of great significance to the assessment of the remaining fatigue life of the entire steel bridge.

This paper reports the fatigue life results of Q420qD high-performance steel cross joints under three working conditions: no treatment, only corrosion treatment, and corrosion and fire treatment, and determines the effects of corrosive media and high temperature on the fatigue strength and fracture characteristics of cross joints.

\section{Specimen design}

The fatigue test object is the cross joint specimen of transverse fillet weld. The base metal is $16 \mathrm{~mm}$ Q420qD steel plate. The chemical composition, mechanical properties, and delivery status of the steel plate meet the relevant requirements of the Chinese high-strength low-alloy structural steels (GB/T 1591-2018), and full thickness sampling is adopted. According to the Chinese metallic materials-fatigue testing-axial force-controlled method code
(GB/T 3075-2008) and the actual test conditions, the specific size of the specimen is determined, as shown in Fig. 1. The model of welding rod is E55, and its mechanical properties are shown in Table 1. Manual arc welding is adopted. The welding voltage is $24 \mathrm{~V}$, the welding current is $150 \mathrm{~A}$, and the welding speed is about $5 \mathrm{~mm} / \mathrm{s}$. The weld quality meets the relevant requirements in the Chinese code for welding of steel structures (GB 50661-2011). The weld leg size is $6 \mathrm{~mm}$ and the calculated weld length is $50 \mathrm{~mm}$. The chemical composition of steel and welding materials is shown in Table 2 .

According to the Chinese metallic materials-tensile testing-Part 1: method of the test at room temperature code (GB/T 208.1-2010), three base metal specimens were made for axial tensile test (see Fig. 2 for dimensions), and the corresponding mechanical property parameters of $\mathrm{Q} 420 \mathrm{qD}$ are measured in Table 3.

\section{Finite-element analysis of fatigue performance of specimen}

Based on ANSYS 15.0 finite-element software, a threedimensional finite-element model of cross joints without corrosion pits and containing corrosion pits is established. SOLID45 solid elements are used, and the fillet weld area elements are all divided by $1 \mathrm{~mm}$ mesh. The weld zone has the same material parameters as $\mathrm{Q} 420 \mathrm{qD}$ high-performance steel: elastic modulus E is $2.064 \times 10^{5} \mathrm{Mpa}$ and Poisson's ratio $\nu$ is 0.3 . Load and boundary conditions: one end is consolidated, and the other end is subjected to a tensile stress surface load of $30 \mathrm{MPa}$.

It can be seen from the stress distribution of the specimen in Fig. 3 that, when the stress distribution of the clamping part is not considered, the maximum equivalent stress of the cross joint specimens without corrosion pits and corrosion pits are located in the weld toe area. In the later fatigue test, most of the cross joint specimens were broken at the weld toe, indicating that the finite-element calculation results can be used as the basis for judging the weak position of

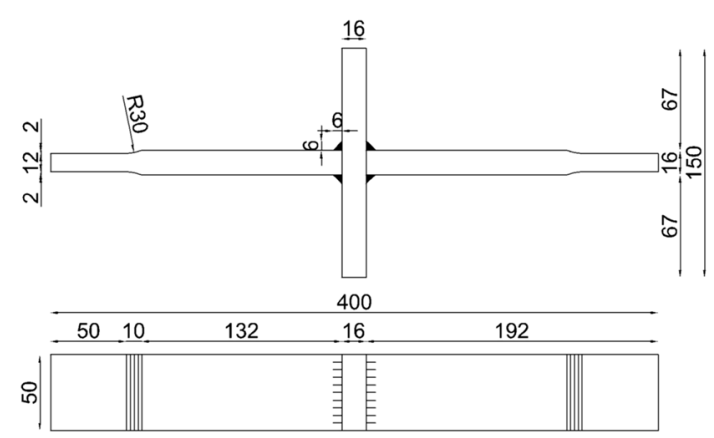

Fig. 1 Size of cross joint test piece (unit: $\mathrm{mm}$ ) 
Table 1 Mechanical properties of E55 electrode deposited metal

\begin{tabular}{lllll}
\hline Electrode & $\begin{array}{l}\text { Tensile strength } \\
R_{m} / \mathrm{MPa}\end{array}$ & $\begin{array}{l}\text { Yield strength } \\
R_{\text {el }} / \mathrm{MPa}\end{array}$ & $\begin{array}{l}\text { Elongation after } \\
\text { fracture } A / \%\end{array}$ & $\begin{array}{l}-30{ }^{\circ} \mathrm{C} \\
\text { impact energy } \\
A_{K V} / J\end{array}$ \\
\hline E55 & $\geq 550$ & $\geq 460$ & $\geq 17$ & $\geq 27$ \\
\hline
\end{tabular}

Table 2 Q420qD steel and E55 electrode chemical composition

\begin{tabular}{lllllllllll}
\hline Material category & \multicolumn{1}{l}{ Content of each component $/ \%$} \\
\cline { 2 - 10 } & $\mathrm{C}$ & $\mathrm{Si}$ & $\mathrm{Mn}$ & $\mathrm{P}$ & $\mathrm{S}$ & $\mathrm{Ni}$ & $\mathrm{Cr}$ & $\mathrm{Nb}$ & $\mathrm{V}$ \\
\hline Q420qD & 0.18 & 0.345 & 1.48 & 0.024 & 0.012 & 0.0085 & 0.022 & 0.005 & 0.07 \\
E55 & $\leq 0.10$ & $\leq 0.80$ & $\leq 1.00$ & $\leq 0.025$ & $\leq 0.015$ & $\leq 0.50$ & $\leq 0.30$ & $\leq 0.20$ & $\leq 0.10$ \\
\hline
\end{tabular}

the specimen, and the rationality of the specimen design is ensured.

\section{Test piece fatigue performance test}

\section{Sample preparation}

Fig. 2 Geometric dimension of cross joint specimen (unit: $\mathrm{mm}$ )

Table 3 Results of material property test

\begin{tabular}{llll}
\hline Specimen number & $\begin{array}{l}\text { Yield strength } \\
f_{y} / M P a\end{array}$ & $\begin{array}{l}\text { Ultimate } \\
\text { strength } \\
f_{u} / M P a\end{array}$ & $\begin{array}{l}\text { Elastic } \\
\text { modulus } \\
E / M P a\end{array}$ \\
\hline Q420qD-1 & 425.803 & 636.446 & $2.069 \times 10^{5}$ \\
Q420qD-2 & 423.535 & 633.281 & $2.058 \times 10^{5}$ \\
Q420qD-3 & 425.172 & 635.567 & $2.064 \times 10^{5}$ \\
Average value & 424.837 & 635.098 & $2.064 \times 10^{5}$ \\
\hline
\end{tabular}
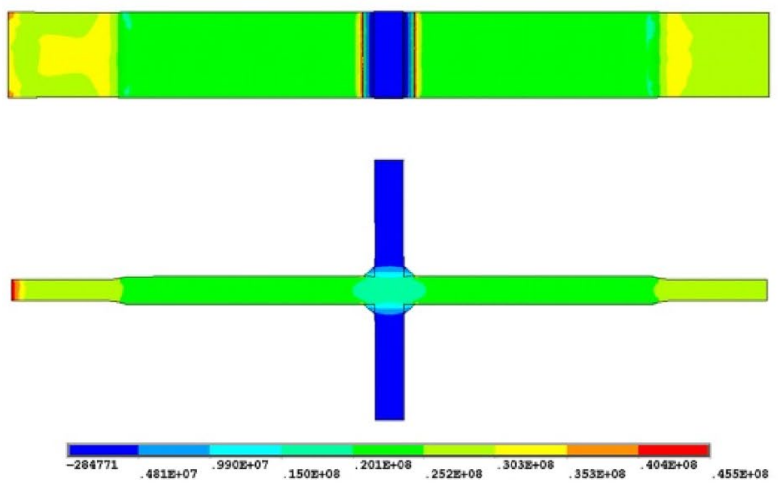

(a) No corrosion pits

Fig. 3 Stress distribution of specimens

\section{Corrosion test}

The cross joint specimens with corrosion pits were obtained by accelerated corrosion test (Xu 2017). Test corrosive environment: $50 \mathrm{~g} / \mathrm{L} \pm 5 \mathrm{~g} / \mathrm{L} \mathrm{NaCl}$ solution was used to simulate the marine atmospheric environment, and $\mathrm{NaOH}$ solution was added to control the $\mathrm{pH}$ value of corrosion chamber in the range of 6.5-7.2. The connection and reaction principle of test equipment are shown in Fig. 4 and Table 4. Pretreatment of corrosion test: in addition to fillet weld area, other parts of the surface are coated with epoxy resin seal to prevent corrosion. In addition, due to the exothermic process and long electrolysis time in the corrosion test, the epoxy resin layer at the corner
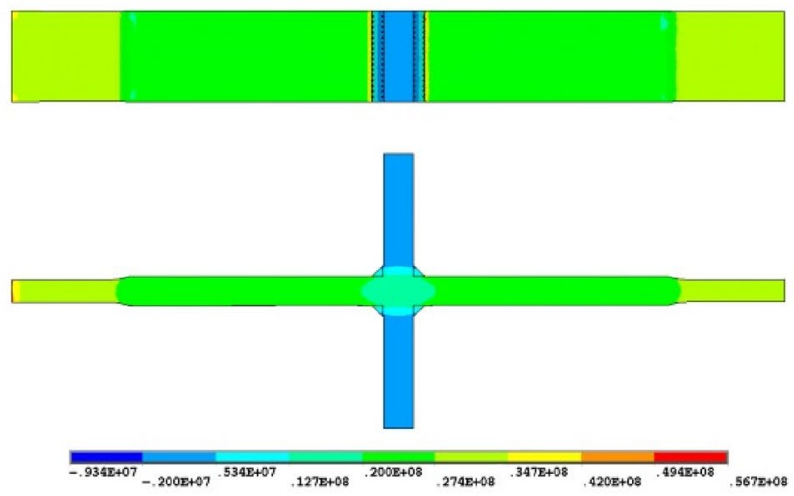

(b) Including corrosion pits 


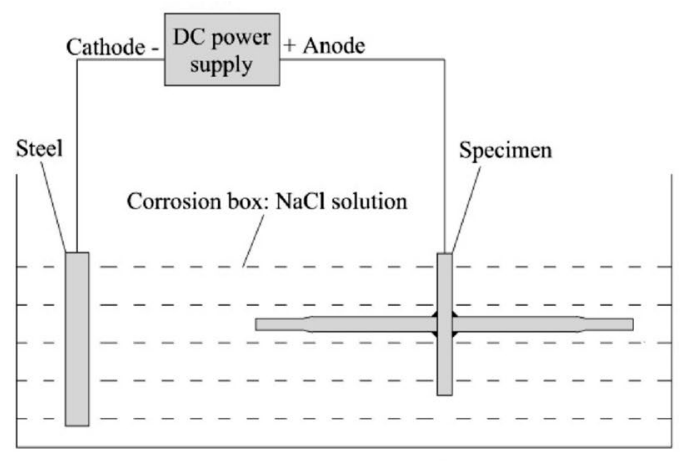

(a) Schematic diagram

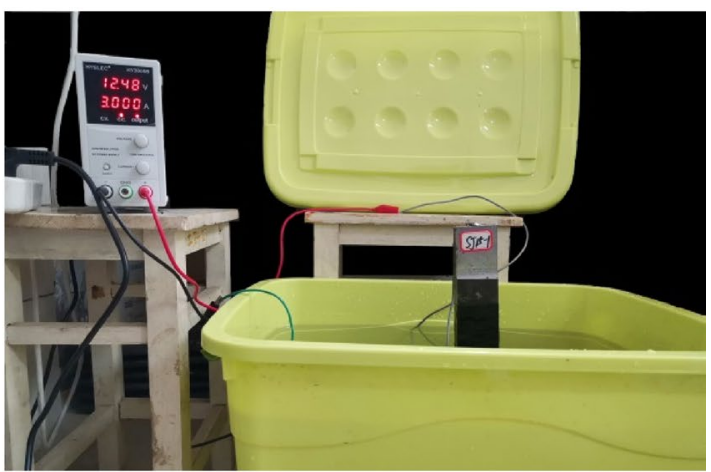

(b) Physical picture

Fig. 4 Equipment connection

Table 4 Reaction principle of electrified accelerated corrosion test

\begin{tabular}{ll}
\hline Classification & Chemical equation \\
\hline Anode & $\mathrm{Fe}-2 e^{-}=\mathrm{Fe}^{2+}$ \\
Cathode & $2 \mathrm{H}_{2} \mathrm{O}+2 e^{-}=\mathrm{H}_{2} \uparrow+2 \mathrm{OH}^{-}$ \\
The total reaction of electrolysis & $\mathrm{Fe}+2 \mathrm{H}_{2} \mathrm{O}=\mathrm{H}_{2} \uparrow+\mathrm{Fe}(\mathrm{OH})_{2}$ \\
\hline
\end{tabular}

Note: Given that $\mathrm{Fe}(\mathrm{OH})_{2}$ is highly unstable, it is easily oxidized, and the final precipitate turns from white to yellowish-green and then quickly turns into reddish-brown. The reaction formula as $4 \mathrm{Fe}(\mathrm{OH})_{2}+\mathrm{O}_{2}+2 \mathrm{H}_{2} \mathrm{O}=4 \mathrm{Fe}(\mathrm{OH})_{3}$.

of the cross joint is easy to be hardened and damaged, resulting in corrosion, which affects the accuracy of the corrosion results. Therefore, it is considered to wrap a layer of electrical tape outside the epoxy resin anti-corrosion coating to achieve the secondary sealing effect.

Pitting corrosion is easy to occur in steel bridges under marine atmospheric environment. Corrosion depth $D_{a}$ is used to evaluate pitting damage, which is expressed as:

$D_{a}=\xi t^{n}$.

In reference (Cao (2005)), the values of ocean atmospheric corrosion depth parameters of many countries in the world are given, and the mean value is taken as the parameter in the power function, i.e., $\xi=0.062, n=0.862$. According to Eq. (1), the average corrosion pit depth of welded joint in marine atmospheric environment for 10 years is $0.45 \mathrm{~mm}$. Then, the relationship between current and time (see Eq. (4)) is obtained using the formula for calculating the average corrosion pit depth (see Eq. (2)) and Faraday's Law (see Eq. (3)). During the energized accelerated corrosion process, the current $I=3 A$ is always controlled. When $T=1.92 h$, the cross joint specimen with the average corrosion pit depth $D=0.45 \mathrm{~mm}$ can be obtained:

$D=\Delta m / S_{0} \rho$
$\Delta m=M I T / F n$

$I T=D S_{0} \rho F n / M$,

where $D$ is the average depth of corrosion pit, $m m ; m$ is the net loss of the test piece before and after the corrosion test, $g$ (after the corrosion test, the corrosion product on the test piece surface is removed with baking soda and white vinegar, wiped clean with absolute ethanol, dried, and weighed); $S_{0}$ is the effective cross-sectional area of the butt weld joint, $\mathrm{mm}^{2} ; \rho$ is the weld material density, $\mathrm{g} / \mathrm{cm}^{3} ; I$ is the corrosion current, $A ; T$ is the time required for corrosion, $s ; M$ is the mole of matter, $\mathrm{g} / \mathrm{mol}$; $F$ is the Faraday constant, $F=9.62 \times 10^{4} \mathrm{C} / \mathrm{mol}$; and $n$ is the number of electrons. Here, given that the anode is $\mathrm{Fe}$, the electrons are lost to $\mathrm{Fe}^{2+}$, so $n=2$.

\section{Fire high-temperature test}

Ten specimens are taken from the corrosion test and placed in the intelligent box-type high-temperature resistance furnace. After setting the target temperature, the temperature will be raised. In the heating section, the points are taken from the ISO-834 standard temperature rise curve (Switzerland. 2019) [see Eq. (5)] for segmented heating. Under the action of high temperature, the yield strength, elastic modulus, and other mechanical parameters of steel will be greatly reduced with the increase of temperature. When the temperature reaches $300{ }^{\circ} \mathrm{C}$, the stress-strain curve of the steel without fireproof layer has no obvious yield step; when the temperature reaches $350{ }^{\circ} \mathrm{C}$, the strength decreases to $2 / 3$ of the original; when the temperature reaches $500{ }^{\circ} \mathrm{C}$, the strength is $1 / 2$ of the original ( $\mathrm{Li} \mathrm{2019),} \mathrm{so} \mathrm{when} \mathrm{the}$ temperature reaches $600{ }^{\circ} \mathrm{C}$, continue to maintain the temperature for $1 \mathrm{~h}$ and then stop heating (Funderburk 1998). At this time, if the specimen is directly taken out to contact 


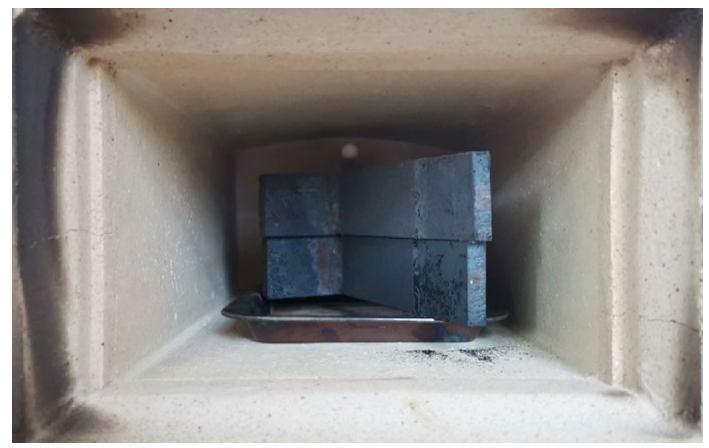

Fig. 5 Cross joint cooling completed

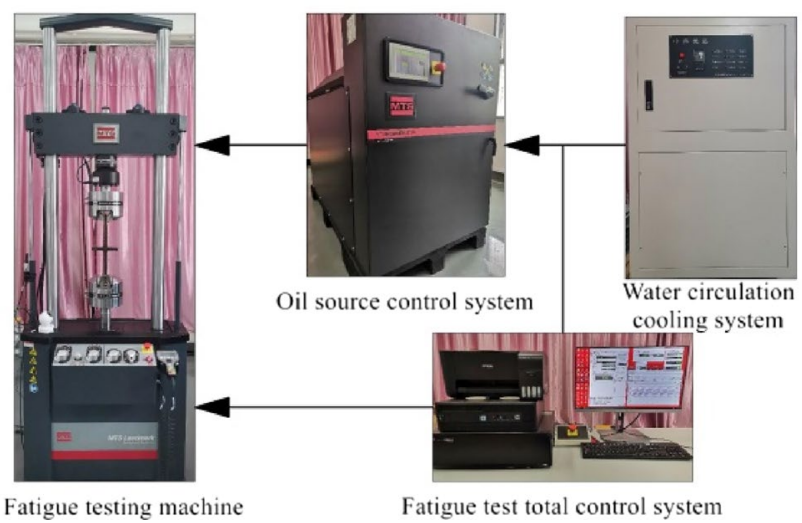

Fig. 6 General system of fatigue test with the external environment for cooling, there will be a large temperature gradient inside the specimen and new additional stress will be generated. Therefore, the cooling process is naturally reduced to room temperature with the resistance furnace. After cooling, the appearance of cross joint is shown in Fig. 5:

$T_{t}=345 \lg (8 t+1)+T_{t 0}$,

where $T_{t}$ is the ambient temperature at the time of fire development to $t,{ }^{\circ} \mathrm{C} ; T_{t 0}$ is the ambient temperature at the time of fire occurrence, $T_{t 0}=20^{\circ} \mathrm{C}$ is taken in this test; and $t$ is the duration of the fire, $\min$.

\section{Test equipment and method}

Fatigue test was carried out on MTS Landmark electrohydraulic servo universal testing machine (see Fig. 6). The load was controlled by force, and the loading waveform was sine wave (China Standard Press 2006) with PVC compensation. The loading frequency varied in the range of $10-15 \mathrm{~Hz}$. The stress ratio $R=0.1$ is the ratio of the minimum stress $S_{\min }$ to the maximum stress $S_{\max }$ in a cycle, i.e., $R=S_{\min } / S_{\max }$. During the test, the system will automatically record the number of loading cycles and the fatigue displacement value at the end of each loading. If there is any abnormality, fracture or the number of cycles reaches 2 million, the test will be stopped. The effective data obtained from the fatigue test of the cross joint are summarized in Table 5.

Table 5 Fatigue life test data of cross joints under different processing conditions

\begin{tabular}{|c|c|c|c|c|c|c|c|c|c|c|c|}
\hline $\begin{array}{l}\text { Speci- } \\
\text { men } \\
\text { number }\end{array}$ & $\begin{array}{c}\Delta S \\
/ M P a\end{array}$ & $\begin{array}{c}F_{a} \\
/ k N\end{array}$ & $\begin{array}{l}F_{m} \\
/ k N\end{array}$ & $\begin{array}{c}N \\
\text { /cycle }\end{array}$ & Forms of destruction & Specimen number & $\begin{array}{c}\Delta S \\
/ M P a\end{array}$ & $\begin{array}{c}F_{a} \\
/ k N\end{array}$ & $\begin{array}{l}F_{m} \\
/ k N\end{array}$ & $\begin{array}{c}N \\
\text { /cycle }\end{array}$ & Forms of destruction \\
\hline SJ1-1 & 96 & 24.89 & 20.36 & $1,491,575$ & Weld toe fracture & SJ8-2 & 143 & 33.14 & 27.12 & 261,473 & Weld toe fracture \\
\hline SJ1-2 & 96 & 24.89 & 20.36 & $1,472,863$ & Weld toe fracture & SJ9-1 & 167 & 38.71 & 31.67 & 151,277 & Weld toe fracture \\
\hline SJ2-1 & 119 & 30.85 & 25.24 & 866,294 & Weld toe fracture & SJ9-2 & 167 & 38.71 & 31.67 & 110,013 & Weld toe fracture \\
\hline $\mathrm{SJ} 2-2$ & 119 & 30.85 & 25.24 & 882,499 & Weld toe fracture & SJ10-1 & 191 & 44.27 & 36.22 & 75,179 & Weld toe fracture \\
\hline SJ3-1 & 143 & 37.08 & 30.33 & 529,826 & Weld toe fracture & SJ10-2 & 191 & 44.27 & 36.22 & 81,278 & Weld toe fracture \\
\hline $\mathrm{SJ} 3-2$ & 143 & 37.08 & 30.33 & 545,400 & Weld toe fracture & SJ11-1 & 96 & 22.25 & 18.20 & 886,604 & Weld toe fracture \\
\hline SJ4-1 & 167 & 43.30 & 35.43 & 316,157 & Weld toe fracture & SJ11-2 & 96 & 22.25 & 18.20 & 860,041 & Weld toe fracture \\
\hline SJ4-2 & 167 & 43.30 & 35.43 & 291,409 & Weld toe fracture & SJ12-1 & 119 & 27.58 & 22.57 & 508,322 & Weld toe fracture \\
\hline SJ5-1 & 191 & 49.52 & 40.52 & 203,963 & Weld toe fracture & SJ12-2 & 119 & 27.58 & 22.57 & 499,182 & Weld toe fracture \\
\hline SJ5-2 & 191 & 49.52 & 40.52 & 167,907 & Weld root fracture & SJ13-1 & 143 & 33.14 & 27.12 & 289,932 & Weld toe fracture \\
\hline SJ6-1 & 96 & 22.25 & 18.20 & 629,946 & Weld toe fracture & SJ13-2 & 143 & 33.14 & 27.12 & 287,118 & Weld toe fracture \\
\hline SJ6-2 & 96 & 22.25 & 18.20 & 534,395 & Weld toe fracture & SJ14-1 & 167 & 38.71 & 31.67 & 195,033 & Weld toe fracture \\
\hline SJ7-1 & 119 & 27.58 & 22.57 & 335,833 & Weld toe fracture & SJ14-2 & 167 & 38.71 & 31.67 & 149,899 & Weld toe fracture \\
\hline SJ7-2 & 119 & 27.58 & 22.57 & 271,230 & Weld toe fracture & SJ15-1 & 191 & 44.27 & 36.22 & 119,715 & Weld toe fracture \\
\hline SJ8-1 & 143 & 33.14 & 27.12 & 177,625 & Weld root fracture & SJ15-2 & 191 & 44.27 & 36.22 & 101,769 & Weld toe fracture \\
\hline
\end{tabular}

SJ1-SJ5 are untreated specimens, SJ6-SJ10 are all corrosion-only specimens, SJ11-SJ15 are corrosion and fire treatment specimens. After that, the untreated specimen, the corrosion treated specimen, and the corroded and fire-treated specimen were simplified to specimen \#1, specimen $\# 2$, and specimen \#3, respectively 


\section{Test results and analysis}

\section{S-Ncurve}

$S-N$ curve is commonly used in engineering in the form of power function, namely:

$C=S^{m} N$.

Take the $\log$ arithm of both sides to get : $m \lg S+\lg N=\lg C$.

After finishing, the deformation is as follows : $\lg N=a-m \lg S$.

where $a$ and $m$ are parameters to be determined by the fitting.

According to the fatigue test data in Table 5, the least square method is used to fit the fatigue life $N$ and stress amplitude $S$ of fillet weld under different treatment conditions. According to IIW specification (Hobbacher 2016), when $N<10^{7}$, the negative inverse slope of $S-N$ curve is taken as $m=3$. Therefore, taking the fitting curve $m=3$, the logarithmic linear expression of cross joint $S-N$ curve under different treatment conditions is obtained. In addition, the $S-N$ curve with $50 \%$ survival rate is obtained from the experimental data, and the logarithmic linear expression of corresponding $S-N$ curve with the $95 \%$ survival rate can be obtained by subtracting 2 times of standard deviation of $\lg N$ $(0.339,0.321$, and 0.340) (Fricke 2012), see Table 6.

The $S-N$ reference curve of welded joint in air is available in steel structure codes of various countries, but the $S-N$ reference curve of welded joint under sea water corrosion or fire high temperature is not included. Although the $S-N$ reference curve of free corrosion of welded joints in air or sea water is provided in the rules of classification societies of various countries, the $S-N$ reference curve of welded

Table 6 Logarithmic linear expression of $S-N$ curve

\begin{tabular}{lll}
\hline Type & Regression of test data & The 95\% survival rate \\
\hline Specimen \#1 & $\lg N=12.153-3 \lg \Delta S$ & $\lg N=11.476-3 \lg \Delta S$ \\
Specimen \#2 & $\lg N=11.746-3 \lg \Delta S$ & $\lg N=11.104-3 \lg \Delta S$ \\
Specimen \#3 & $\lg N=11.907-3 \lg \Delta S$ & $\lg N=11.227-3 \lg \Delta S$ \\
\hline
\end{tabular}

joints after high-temperature fire is not specified. Therefore, the $S-N$ curves of welded joints after corrosion and fire treatment are evaluated based on the steel structure design codes of various countries and classification societies. See Table 7 for $S-N$ reference curve of cross joint in various specifications under different treatment types.

For the convenience of comparison, the $S-N$ curve of specimen \#1, specimen \#2, and specimen \#3, the fitting curve under the $95 \%$ survival rate, and the $S-N$ fatigue curve of national codes are plotted in Fig. 7, and the 2 million cycle fatigue limit value of fillet weld under corresponding conditions is calculated, as shown in Table 8.

It can be seen from Fig. 7 and Table 8 that:

1. The test fatigue limit values of specimen $\# 2$ and specimen \#3 are $26.83 \%$ and $17.21 \%$ lower than that of specimen \#1, respectively. Corrosion will increase the stress concentration on the surface of the test piece, resulting in a decrease in the fatigue performance of the cross joint; when the fire temperature is about $600^{\circ} \mathrm{C}$, the high temperature of the fire will increase the fatigue performance of the cross joint (Wang et al. 2020c).

2. For specimen \#1, the fatigue limit value under the $95 \%$ survival rate is $53.09 \mathrm{MPa}$, which is $11.38 \%$ lower than that calculated by ABS code and $6.18 \%$ higher than that calculated by DNV code. The fatigue limit value of specimen \#1 is $25.47 \%, 11.58 \%$, and $41.68 \%$ higher than the theoretical design value of GB code, EN code, and IIW code, which is equivalent to the theoretical design value of ANSI code. Comparatively speaking, IIW code obviously underestimates the fatigue of cross joint Working life. Compared with ANSI code, EN code design curve can better predict its fatigue life and has enough safety reserve. However, when the number of cycles is less than 200,000 , more fatigue test data are needed.

3. For specimen \#2, the fatigue limit value is higher than the theoretical value calculated by the classification societies of various countries. The main reason is that the corrosion time of the welded joint in the environment is not considered in the calculation formula of the national codes. The fatigue limit value of specimen \#2 is $11.35 \%$

Table $7 S-N$ reference curve of cross joint in national codes under different treatment types

\begin{tabular}{lllll}
\hline Type & Standard & Formula & Standard & Formula \\
\hline Atmospheric corrosion & GB code $(2017)$ & {$[\Delta \sigma]=\left(\frac{0.72 \times 10^{12}}{N}\right)^{1 / 3}$} & ANSI code $(2010)$ & $F_{S R}=\left(\frac{14.4 \times 10^{11}}{n_{S R}}\right)^{0.333}$ \\
& EN code $(2005)$ & $\lg N=12.010-3 \lg \Delta \sigma$ & ABS code $(2013)$ & $N=4.30 \times 10^{11} \times S^{-3}$ \\
& IIW code (2016) & $\lg N=11.699-3 \lg \Delta \sigma$ & DNV code $(2014)$ & $\lg N=11.398-3 \lg \Delta \sigma$ \\
Seawater corrosion & ABS code & $N=1.43 \times 10^{11} \times S^{-3}$ & DNV code & $\lg N=10.921-3 \lg \Delta \sigma$ \\
& CCS code (2013) & $\lg N=11.155-3 \lg \Delta \sigma$ & GJB code $(1999)$ & $\lg N=11.261-3 \lg \Delta \sigma$ \\
\hline
\end{tabular}


lower than the theoretical design value of GJB code and $15.09 \%$ higher than the theoretical design value of DNV code under the $95 \%$ survival rate, which is equivalent to the theoretical calculation value of ABS code and CCS code.

4. For specimen \#3, the fatigue limit value is $73.90 \mathrm{MPa}$, which is not different from the theoretical calculation value of GB code, and the fatigue life of specimen \#3 is predicted by the design curve of GB code, which has sufficient safety reserve. The fitting curve of specimen
\#3 under the $95 \%$ survival rate is in good agreement with the design curve of GJB code.

\section{Fatigue fracture analysis}

\section{Macro analysis}

It can be seen from Fig. 8 that the fracture morphology has typical fatigue fracture characteristics, and the instantaneous section is rough and tear like. Before instantaneous break, the section is smooth and flat. The fatigue fracture

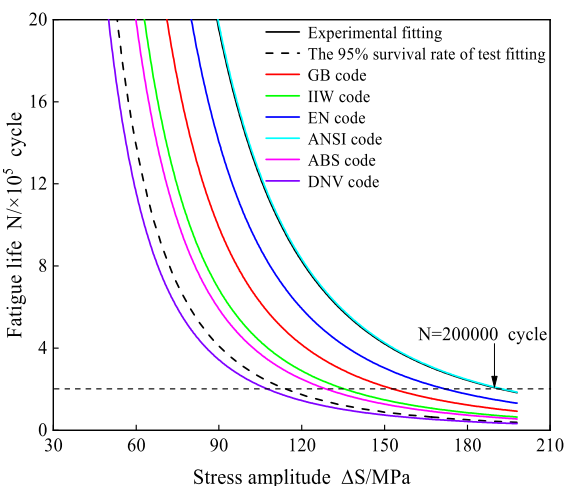

(a) $S$ - $N$ curve of specimen \#1

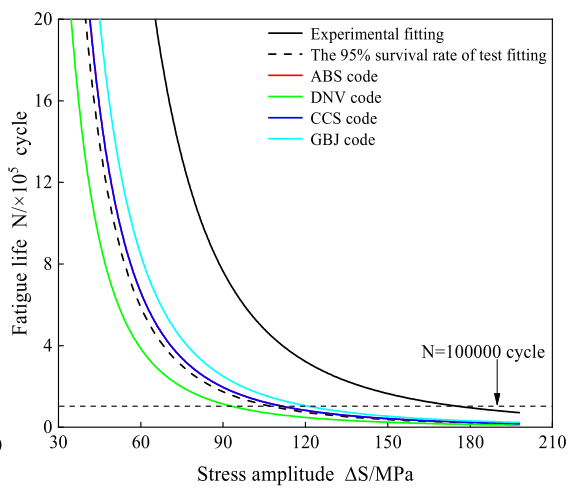

(b) $S$ - $N$ curve of specimen \#2

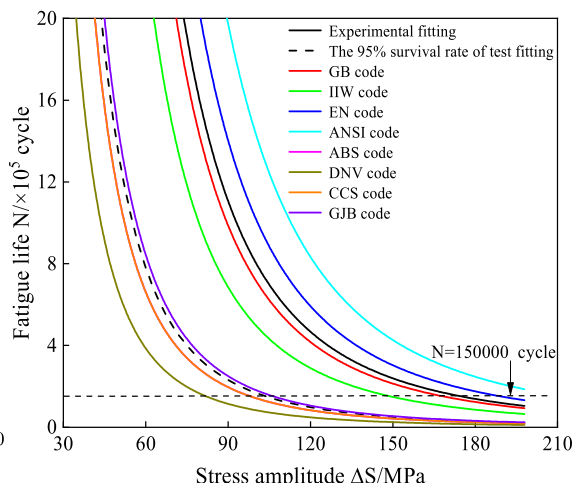

(c) $S$-N curve of specimen \#3

Fig. $7 S-N$ curve comparison

Table 8 Comparison of fatigue limit values

\begin{tabular}{lllll}
\hline Type & Test fitting/specification & Fatigue limit & Test fitting/specification & Fatigue limit \\
\hline Specimen \#1 & Experimental fitting & $89.26 \mathrm{MPa}$ & The 95\% survival rate & $53.09 \mathrm{MPa}$ \\
& GB code & $71.14 \mathrm{MPa}$ & ANSI code & $89.63 \mathrm{MPa}$ \\
& EN code & $80.00 \mathrm{MPa}$ & ABS code & $59.91 \mathrm{MPa}$ \\
& IIW code & $63.00 \mathrm{MPa}$ & DNV code & $50.00 \mathrm{MPa}$ \\
Specimen \#2 & Experimental fitting & $65.31 \mathrm{MPa}$ & The 95\% survival rate & $39.90 \mathrm{MPa}$ \\
& ABS code & $41.51 \mathrm{MPa}$ & DNV code & $34.67 \mathrm{MPa}$ \\
& CCS code & $41.51 \mathrm{MPa}$ & GJB code & $45.01 \mathrm{MPa}$ \\
Specimen \#3 & Experimental fitting & $73.90 \mathrm{MPa}$ & The 95\% survival rate & $43.85 \mathrm{MPa}$ \\
\hline
\end{tabular}

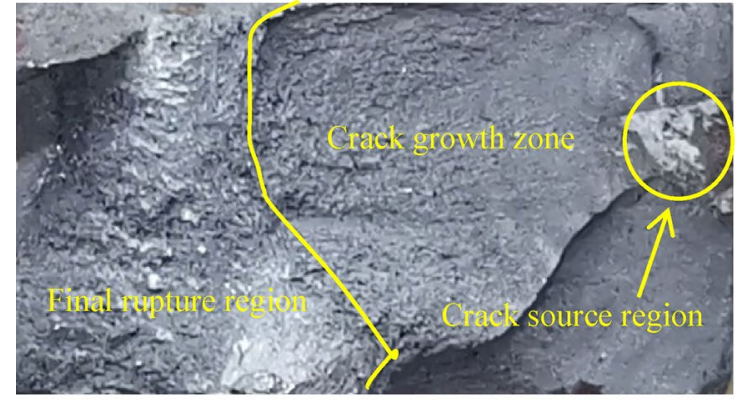

(a) Weld toe fracture

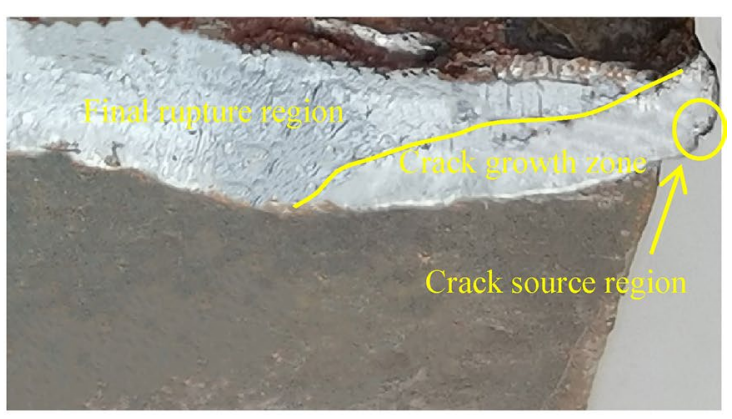

(b) Weld root fracture

Fig. 8 Macroscopic morphology of fatigue fracture surface of cross joint 
is divided into three parts: crack source area, crack growth area, and fracture area. As the initial point of fatigue failure, the crack source area is smooth and fan-shaped, and radiates slowly to the surrounding area, which is relatively smooth. The fracture surface of crack propagation zone is smooth and smooth with convex wavy lines. According to the spacing of corrugated lines, it is obvious that the crack growth velocity near the crack source is faster than that far away from the crack source. The surface of the crack instantaneous fracture zone is rough and uneven, and there is a certain inclination angle with the main section. With the crack propagation, the effective section of the member is weakened. When the stress reaches the ultimate strength, the cross joint will break instantaneously.

\section{Micro analysis}

To observe the micro-failure mode of the fatigue fracture, the fracture surface was scanned by HITACHI SU8010 cold field-emission scanning electron microscope. The microfracture morphology is shown in Fig. 9. After high magnification, it is found that the cross-section of the crack source area is relatively flat and smooth, and the crack extends from the core to the surrounding, and there may be multiple crack sources at the same time. There are many arc fatigue bands
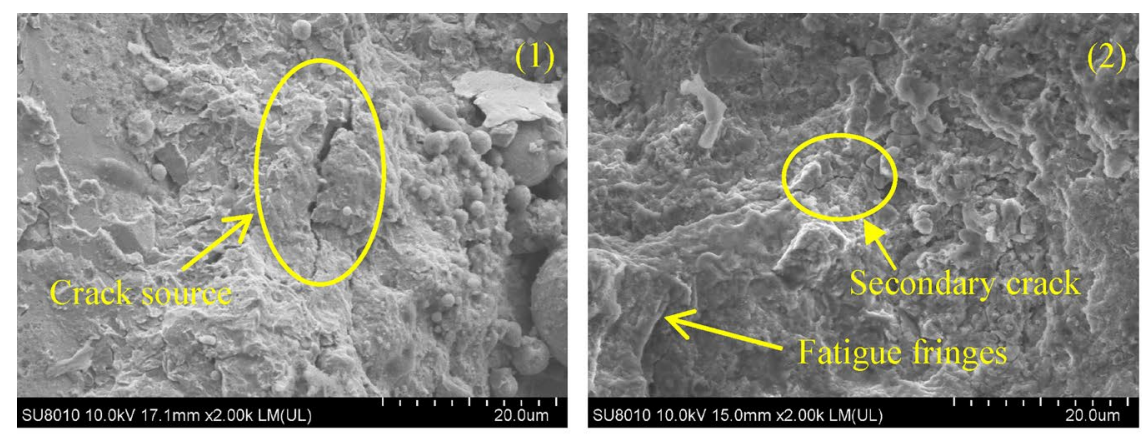

(a) No treatment
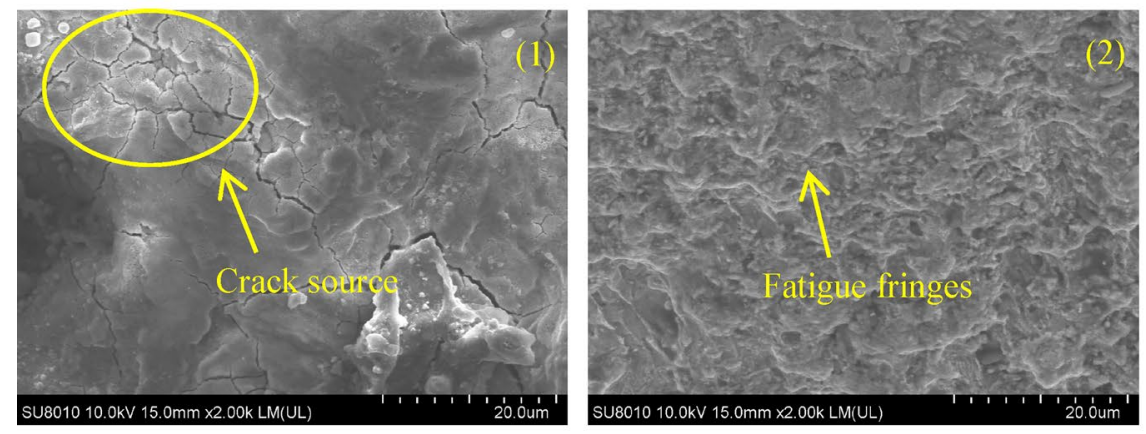

(b) Corrosion treatment only
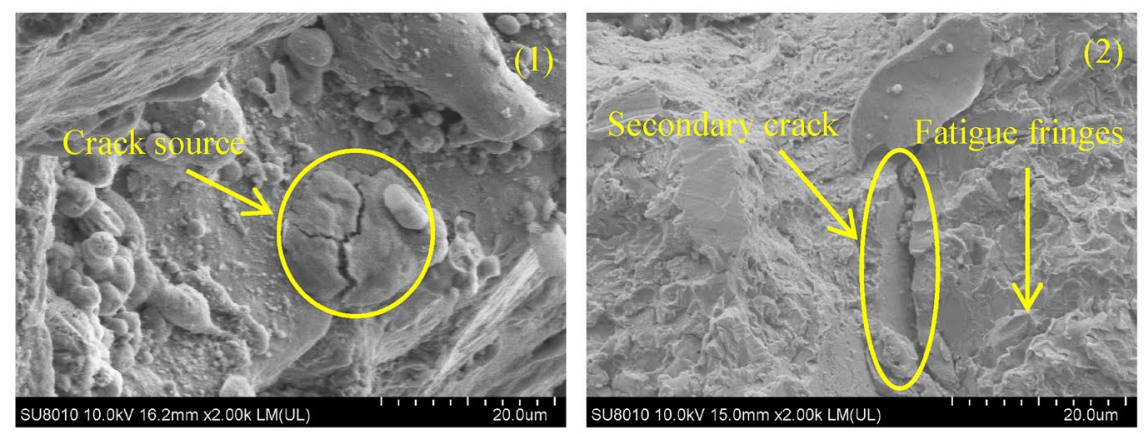

(c) Corrosion and fire treatment
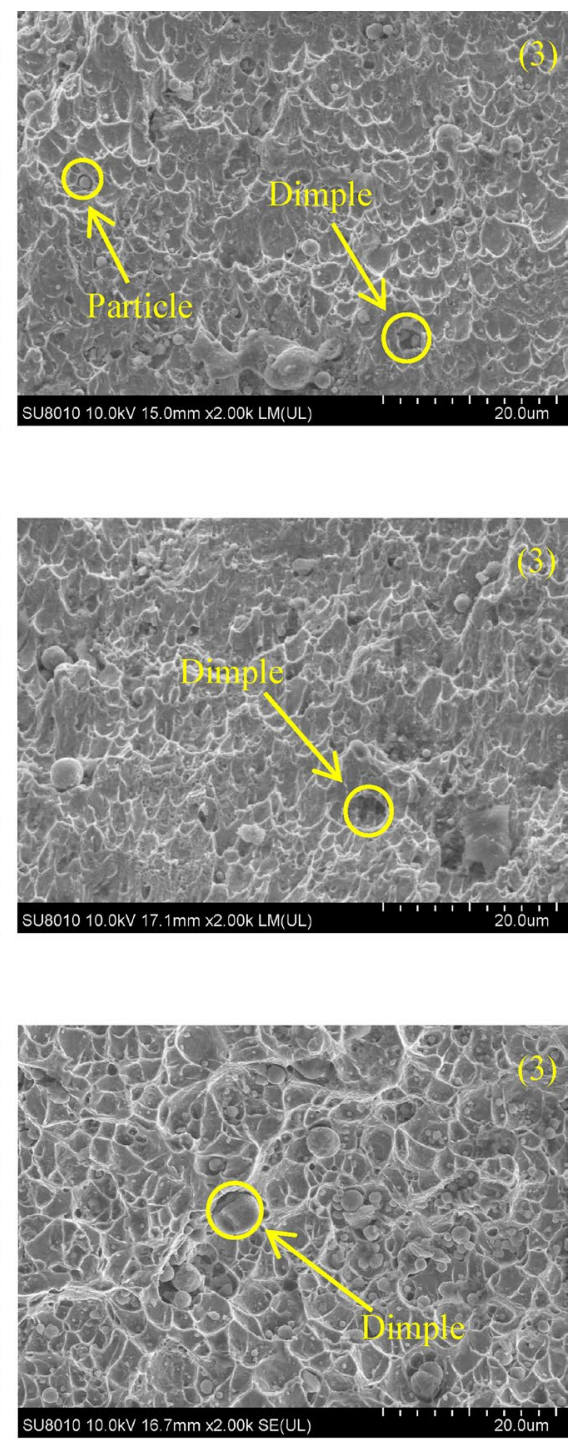

SU8010 10.0kV $16.7 \mathrm{~mm} \times 2.00 \mathrm{~K}$ SE(UL)

1-Crack source region; 2-Crack growth zone; 3-Final rupture region

Fig. 9 Fatigue fracture morphology of cross joint 
protruding forward in the crack growth zone. Due to different crack sources or different crack growth rates, secondary cracks can be observed in some fractures, and the spacing of fatigue bands at the same fracture increases with the increase of crack growth rate. There are many round or ellipse dimples with different sizes in the instantaneous fracture zone, and some dimples also contain inclusions or particles, which indicates that the material fracture is ductile fracture. Moreover, the existence of dimples indicates that the material is not easy to slip in the process of growth, and the rapid growth stage is not enough, which accounts for a small proportion of the fatigue life. Affected by corrosion, the fracture of the specimen contains multiple crack sources (Liu et al. 2021). After the high temperature of the fire, secondary cracks at a certain angle to the fracture can be seen at the fracture of the specimen. The number of dimples is reduced, but the size of the dimples is relatively larger (Zhang et al. 2020).

\section{Fatigue damage analysis}

Figure 10 shows the fatigue displacement curve of the specimen SJ4-2, where $\delta$ is the displacement variation of the specimen, and $\mathrm{n}$ and $\mathrm{N}$ represent the number of cycles and fatigue life of the specimen, respectively. It can be seen that the displacement change of the specimen can be divided into two stages. The first stage is the steady-state crack growth stage, and the overall displacement change is small in this stage, which is basically in a stable state, accounting for about $90 \%$ of the whole fatigue life. The second stage is the stage of unstable crack growth, and the displacement growth rate is obviously accelerated. With the gradual propagation of the crack, the effective bearing section of the specimen decreases rapidly. Finally, the cross-section stress under the

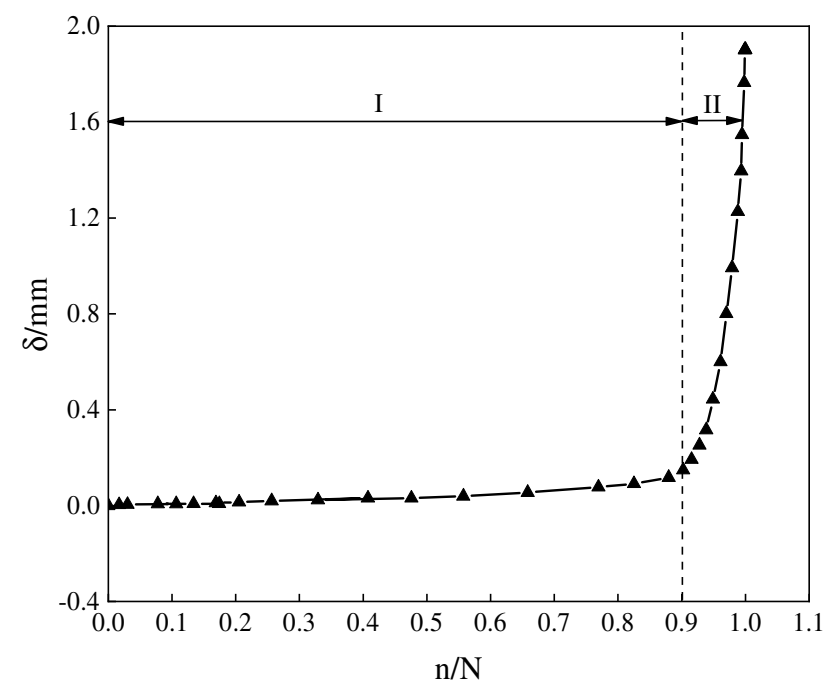

Fig. 10 Fracture morphology of cross joint external cyclic load is greater than the ultimate strength of the material, resulting in instantaneous fracture. The proportion of the instantaneous fracture stage in the fatigue life is very small, indicating that the unstable propagation stage of the crack is not sufficient.

In damage mechanics, as an internal variable, damage is used to represent the deterioration of metal materials. The constitutive equation and evolution equation of metal materials are constituted by the internal variable and load parameters to describe the deterioration process of metal materials (Li 1992). Therefore, the damage can be used to predict the residual life of metal materials, and to replace or dismantle the metal structure with low life, so as to ensure that the metal structure can be used safely during the operation period. For high cycle fatigue, assuming that the damage variable remains constant in a stress cycle, i.e., incremental linear, the cumulative fatigue damage $D_{f}$ caused by fatigue fringes of fatigue fringes of dimple dimple secondary cracks in a stress cycle is (Lou 1991):

$D_{f}=1-\left(1-\frac{N}{N_{f}}\right)^{1 /(\beta+2)}$

$N_{f}=\frac{(\beta+1)\left(S_{\max }^{\beta+1}-S_{\min }^{\beta+1}\right)^{-1}}{2 B(\beta+2)}$,

where $B$ and $\beta$ are material constants, which can be determined by the fatigue test results; $N_{f}$ is the fatigue life.

The fitting result of fatigue test shows that $\beta=2$. According to Eq. (9), the change curve of cumulative damage with cycle ratio is drawn, as shown in Fig. 11. It can be seen that with the increase of $N / N_{f}$, the degree of fatigue damage

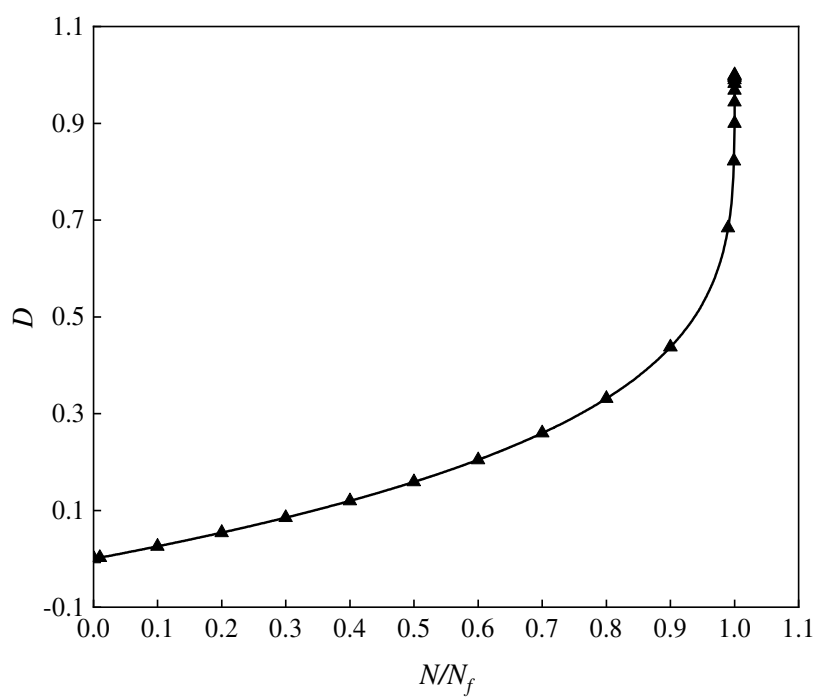

Fig. 11 Fatigue displacement curve 
is also increasing, and the increase rate of damage is also increasing continuously, which is consistent with the phenomenon that the fatigue band spacing of micro-fracture increases gradually under high-power microscope. When $0<N / N_{f}<0.9$ is the stage of crack propagation, the $D$ value before fracture of cross joint is about 0.45 , and the cumulative damage is large. When $0.9 \leq N / N_{f}<1.0$, the increasing rate of $D$ value of cross joint is obviously accelerated, which is the instantaneous breaking stage. This is consistent with the displacement change characteristics of fatigue displacement curve in Fig. 10 at the second stage, which shows that the theoretical results are consistent with the experimental results.

\section{Conclusion}

This paper conducted fatigue test research under three working conditions, deeply studied the influence of corrosive media and high temperature of fire on the fatigue performance of Q420qD high-performance steel cross joints, and reached the following conclusions:

1. The fatigue limit value of the cross joint is reduced after being affected by corrosion, and its fatigue limit value is increased after being subjected to the $600{ }^{\circ} \mathrm{C}$ high temperature of fire.

2. For the cross joint specimen, the fatigue life without treatment can be well predicted using the design curve of EN code, and there is enough safety reserve; The fitting curve of $95 \%$ survival rate in corrosion treatment is not different from that in ABS code and CCS code; The fatigue life of corrosion and fire treatment can be estimated by the design curves of GB code safely, and the fitting curve under $95 \%$ survival rate is in good agreement with the design curves of GJB code.

3. Corrosion will increase the source of fatigue cracks. After the $600{ }^{\circ} \mathrm{C}$ high temperature of fire, the relative size and number of dimples in the instantaneous failure zone are larger. The fatigue damage analysis results are basically consistent with the change law of the fatigue displacement curve, and conform to the microscopic morphology characteristics of the fatigue fracture.

Acknowledgements The authors are incredibly grateful to the Mechanics Laboratory of East China Jiaotong University for providing a fatigue testing machine.

Author contributions Conceptualization, HGC; investigation and stress test, $\mathrm{CH}$; methodology, $\mathrm{CH}$; data curation, $\mathrm{YJ}$; writing-original draft preparation, $\mathrm{CH}$; writing-review and editing, $\mathrm{CH}, \mathrm{HGC}$, and $\mathrm{YJ}$.
Funding This research was funded by the National Natural Science Foundation of China (Grant No. 51368018, 51968024).

\section{Compliance with ethical standards}

Conflict of interest The authors declare no conflict of interest.

Open Access This article is licensed under a Creative Commons Attribution 4.0 International License, which permits use, sharing, adaptation, distribution and reproduction in any medium or format, as long as you give appropriate credit to the original author(s) and the source, provide a link to the Creative Commons licence, and indicate if changes were made. The images or other third party material in this article are included in the article's Creative Commons licence, unless indicated otherwise in a credit line to the material. If material is not included in the article's Creative Commons licence and your intended use is not permitted by statutory regulation or exceeds the permitted use, you will need to obtain permission directly from the copyright holder. To view a copy of this licence, visit http://creativecommons.org/licenses/by/4.0/.

\section{References}

ABS 115 NOTICE 1-2013. (2013). Commentary on the guide for the fatigue assessment of offshore structures. Houston: ABS Plaza.

ANSI, AISC 360-10. (2010). Specification for structural steel buildings. Chicago: American Institute of Steel Constrction.

Azari-Dodaran, N., \& Ahmadi, H. (2019). Structural behavior of rightangle two-planar tubular TT-joints subjected to axial loadings at fire-induced elevated temperatures. Fire Safety Journal, 108, 102841-102849.

Azhari, F., Heidarpour, A., Zhao, X. L., Hutchinsonbet, R., \& C. . (2017). Post-fire mechanical response of ultra-high strength (Grade 1200) steel under high temperatures: Linking thermal stability and microstructure. Thin-Walled Structures, 119, 114-125.

Bhandari, J., Khan, F., Abbassi, R., Garaniya, V., \& Ojeda, R. (2015). Modelling of pitting corrosion in marine and offshore steel structures-a technical review. Journal of Loss Prevention in the Process Industries, 37, 39-62.

Cao, C. N. (2005). Natural environmental corrosion of materials in China. Beijing: Chemical Industry Press.

China Classification Society. (2013). Guidelines for fatigue strength assessment of offshore engineering structures. Beijing: People's Communications Press.

Cui, C., Zhang, Q. H., Bao, Y., Kang, J. P., \& Bu, Y. Z. (2018). Fatigue performance and evaluation of welded joints in steel truss bridges. Journal of Constructional Steel Research, 148, 450-456.

Daryan, A. S., \& Yahyai, M. (2009). Behaviour of welded top-seat angle connections exposed to fire. Fire Safety Journal, 44(4), 603-611.

DNVGL-RP-0005. (2014). Fatigue design of offshore steel structures. Norway: DNV.

EN 1993-1-9. (2005). Eurocode 3:design of steel structures part 1-9: fatigue. Brussels: European Committee for Standardization.

Fricke, W. (2012). IIW Recommendations for the fatigue assessment of welded structures by notch stress analysis. Cambridge: Woodhead Publishing.

Funderburk, R. S. (1998). Posted heat treatment. Welding. Innovation, 15(2), 1-2.

Garbatov, Y., Soares, C. G., \& Parunov, J. (2014). Fatigue strength experiments of corroded small scale steel specimens[J]. International Journal of Fatigue, 59(03), 137-144. 
GB/T 20120.1-2006. (2006). Corrosion of metals and alloys-corrosion fatigue testing-Part 1: cycles to failure testing. Beijing: China Standard Press.

GB50017-2017. (2017). Code for design of steel structure. Beijing: China Planning Press.

Giorgetti, V., Santos, E. A., Marcomini, J. B., \& Sordi, V. L. (2019). Stress corrosion cracking and fatigue crack growth of an API 5L $\mathrm{X} 70$ welded joint in an ethanol environment. International Journal of Pressure Vessels \& Piping, 169, 223-229.

GJB, Z 119-99. (1999). Method for structural design and strength calculation of naval surface ships. Beijing: General Equipment Department of PLA.

Gkatzogiannis, S., Weinert, J., Engelhardt, I., Knoedela, P., \& Ummenhofera, T. (2019). Correlation of laboratory and real marine corrosion for the investigation of corrosion fatigue behaviour of steel components. International Journal of Fatigue, 126, 90-102.

Hobbacher, A. (2016). Recommendations for Fatigue Design of Welded Joints and Components. New York: Welding Research Council New York,WRC-Bulletin 520.

Huang, W., Garbatov, Y., \& Soares, C. G. (2014). Fatigue reliability of a web frame subjected to random non-uniform corrosion wastage. Structural Safety, 48, 51-62.

ISO 834-2-2019. (2019). Fire-resistance tests-elements of building construction. Switzerland: ISO.

Jia, Z. Y., Yang, Y., He, Z., Ma, H. B., \& Ji, F. (2019). Mechanical test study on corroded marine high performance steel under cyclic loading. Applied Ocean Research, 93, 101942.

Jiang, J., Chiew, S. P., Lee, C. K., \& Tiong, P. L. Y. (2017). A numerical study on residual stress of high strength steel box column. Journal of constructional steel research, 128, 440-450.

Kang, D., Lee, J., \& Kim, T. (2011). Corrosion fatigue crack propagation in a heat affected zone of high-performance steel in an underwater sea environment. Engineering Failure Analysis, 18(2), $557-563$

Kim, I., Lee, M., Ahn, J., \& Kainuma, S. (2013). Experimental evaluation of shear buckling behaviors and strength of locally corroded web. Journal of constructional steel research, 83, 75-89.

Klinesmith, D. E., McCuen, R. H., \& Albrecht, P. (2007). Effect of environmental conditions on corrosion rates. Journal of Materials in Civil Engineering, 19(2), 121-129.

Langschwager, K., Rudolph, J., Scholz, A., \& Oechsner, M. (2017). High temperature fatigue of welded joints-experimental investigation and local analysis of butt welded flat and cruciform specimens. Journal of Pressure Vessel Technology, 139, 41408.

Li, B. Y. (2019). Similarity theory research for the fire testing of reduced scale steel structure. Beijing: China Academy of Building Research.

Li, H. (1992). Fundamentals of damage mechanics. Jinan: Shandong science and Technology Press.

Li, Z., Zhang, D. C., Wu, H., Huang, F. H., Hong, W., \& Zang, X. S. (2018). Fatigue properties of welded Q420 high strength steel at room and low temperatures. Construction and Building Materials, 189, 955-966.

Liu, B. X., Gao, C. R., Zheng, W. C., Gao, X. H., Zhu, C. L., \& Li, S. J. (2018). Development of Q420qD bridge steel with high toughness. China Metallurgy, 28(2), 67-72.

Liu, X. H., Xiao, L. F., Cai, C. S., Zhang, J., \& Wang, L. (2021). Fatigue properties investigation of corroded high-performance steel specimens. Journal of Materials in Civil Engineering, 33(1), 4020410.

Lou, Z. W. (1991). Fundamentals of damage mechanics. Chengdu: Xi' an Jiaotong University Press.

Luo, P. J., Zhang, Q. H., Bao, Y., \& Bu, Y. Z. (2019). Fatigue performance of welded joint between thickened-edge U-rib and deck in orthotropic steel deck. Engineering Structures, 181, 699-710.
Radu, D., Glanu, T., \& Sedmak, S. (2018). Structural integrity of butt welded connection after fire exposure. Procedia Structural Integrity, 13, 1082-1087.

Radu, D., Glanu, T., \& Sedmak, S. (2019). Butt welded joints assessment after fire exposure. Engineering Failure Analysis, 106, 104144.

Song, Q. Y., Heidarpour, A., Zhao, X. L., \& Han, L. H. (2016). Postearthquake fire behavior of welded steel I-beam to hollow column connections: an experimental investigation. Thin-Walled Structures, 98, 143-153.

Su, H., Wang, J., \& Du, J. (2019). Experimental and numerical study of fatigue behavior of bridge weathering steel Q345qDNH. Journal of Constructional Steel Research, 161, 86-97.

Thierry, D., Vucko, F., Luckeneder, G., Weber, B., Dosdat, L., Bschorr, T., \& Rother, K. (2016). Fatigue behavior of spot-welded joints in air and under corrosive environments. Welding in the World, 60(6), 1211-1229.

Tohidi, S., \& Sharifi, Y. (2016). Load-carrying capacity of locally corroded steel plate girder ends using artificial neural network. Thin Walled Structures, 100, 48-61.

Walters, C. L., Alvaro, A., \& Maljaars, J. (2016). The effect of low temperatures on the fatigue crack growth of S460 structural steel. International Journal of Fatigue, 82(1), 110-118.

Wang, D. P., Hu, D. J., Deng, C. Y., Wu, S. P., \& Gao, Z. W. (2020a). Effect of heat treatment combined with ultrasonic impact on fatigue property of Q345B steel welded joint. Transactions of the China Welding Institution, 41(04), 6-11.

Wang, W. D., Jiang, Y., Hu, C., Cheng, H. G., \& Xie, L. (2020b). Numerical analysis of butt weld fatigue performance in complex environment. Highway, 65(05), 155-159.

Wang, W. Y., Zhang, J., \& Qin, S. Q. (2018). Analysis on residual stress in welded steel sections in fire //[C] The 16th academic exchange conference and teaching seminar of structural stability and fatigue branch of china steel structure association. Qingdao, China: Institute of Structural Stability and Fatigue, China Steel Construction Society.

Wang, W. Y., Zhang, J., \& Yang, Z. L. (2020c). Experimental study on residual stress in high strength Q690 welded steel sections after high temperature exposure. Journal of Building Structure, 41(10), 86-93.

$\mathrm{Xu}, \mathrm{P}$. (2017). Meso experimental study on corrosion expansion of reinforced concrete under electrified, dry wet and salt spray conditions. Shenzhen: Shenzhen University.

Yamaguchi, E., Akagi, T., \& Tsuji, H. (2014). Influence of corrosion on load-carrying capacities of steel I-section main-girder end and steel end cross-girder. International Journal of Steel Structures, 14(4), 831-841.

Yang, S., Yang, H. Q., Liu, G., Huang, Y., \& Wang, L. D. (2016). Approach for fatigue damage assessment of welded structure considering coupling effect between stress and corrosion. International Journal of Fatigue, 88, 88-95.

Zhang, C. T., Jin, H. L., \& Zhu, L. (2020). Experimental study on fatigue properties of Q345 steel after natural cooling at high temperature. Journal of Building Structure, 41(10), 78-85.

Zhang, D. C., Li, Z., Wu, H. Y., \& Huang, F. H. (2018). Experimental study on fatigue behavior of Q420 high-strength steel at low temperatures. Journal of Constructional Steel Research, 145, $116-127$.

Zhang, X., Liu, H., Guo, Z. H., Wang, F. H., Yang, J. W., \& Yong, Q. L. (2016). Performance control of Q420qE high strength bridge steel joint. Electric Welding Machine, 46(9), 1-6.

Zhao, T. L., Liu, Z. Y., Du, C. W., Sun, M. H., \& Li, X. G. (2018). Effects of cathodic polarization on corrosion fatigue life of E690 steel in simulated seawater. International Journal of Fatigue, 110, $105-114$. 
Zhu, M. C., \& Li, G. Q. (2017). Behavior of beam-to-column welded connections in steel structures after fire. Procedia Engineering, 210, 551-556.

Zong, L., Shi, G., Wang, Y. Q., Li, Z. X., \& Ding, Y. (2017). Experimental and numerical investigation on fatigue performance of non-load-carrying fillet welded joints. Journal of Constructional Steel Research, 130, 193-201.
Publisher's Note Springer Nature remains neutral with regard to jurisdictional claims in published maps and institutional affiliations. 